\title{
BIOCHEMICAL AND HEMATOLOGICAL BIOMARKER IN SCIENCE DETERMINED IN FEMALE ALBINO RATS INDUCED WITH INFERTILITY AND ADMINISTERED WITH ANTHOCLIESTA VOGELII
}

\section{${ }^{1}$ Department of Biochemistry, Faculty of Science, Lagos State University, Nigeria \\ ${ }^{2}$ Department of Chemistry, Faculty of Science, University of Lagos, Nigeria \\ Correspondence \\ Oladimeji S.O $1^{*}$, Department of Biochemistry, Faculty of Science, Lagos State University, Nigeria.}

Oladimeji S.O ${ }^{*}$, Lawal O.A. and Steve A

email: olugbenga.oladimeji@lasu.edu.ng

\section{Funding information}

\begin{abstract}
:
Introduction: Anthocleista vogelii soaked in ethanol among other solvent has been used traditionally for the acclaimed fertility enhancing properties especially in females

Aims: This research was to investigate the claims from the traditional uses of Anthocliesta vogelii in enhancing fertility so as to provide scientific parameters to justify such assertions.

Materials and Methods: The phytochemistry of the ethanolic leave extract of Anthocleista vogelii was determined prior to it being administered orally for 14 days to Wister albino rats. Micronor (norethisterone) or Nacetylcysteine (NAC) was given orally to induce temporary infertility in the female rats for seven (7) days prior to other treatment. The Blood samples from experimental animal groups were collected through cardiac puncture when the rats were sacrificed after the completion of fourteen (14) days extract administration. The hematological parameters were performed using the Sysmex ${ }^{\circledR}$ Automated Hematology Analyzer KX-21N. Biochemical evaluation of glutamic pyruvate transaminase ALT, alkaline phosphatase ALP, glutamic oxaloacetate transaminase AST, total cholesterol and total tryacylglycerol were done using Randox $\circledast$ biochemical kits.

Results: The extract was found to possess Anthraquinones, Terpenoids, Flavonoids, Saponins, Alkaloids, Phenols and Phytosterols. The hematological parameters showed a significant increase $(P<0.05)$ in absolute middle cells (basophils, eosinophils and monocytes) count. It also showed a significant reduction in the ALP, ASP, AST, TAG and cholesterol level $(p<0.05)$.

Conclusion: The results suggest that Anthocleista vogelii may play a role in creating the environment required for enhancing pregnancy and support the claims on the traditional use of Anthocliesta vogelii to enhance fertility in female.

Keywords: Ethanolic extract, Anthocleista vogelii, WBC, RBC, female fertility, ALT, ASP, ALP, triacylglycerol, cholesterol, lymphocyte
\end{abstract}

(C) 2018 The Authors. Journal of Research and Reviews in Science - JRRS, A Publication of Lagos State University 


\section{INTRODUCTION}

Reproductive health is a state of complete physical mental and social well-being and not merely the absence of disease or infirmity in all matters relating to the reproductive system and to its functions and processes. Infertility is a problem of global proportions; worldwide more than 70 million couples suffer from infertility. The current evidence indicates $9 \%$ prevalence of infertility (of 12 months) with $56 \%$ couples seeking medical care in more developed and $51.2 \%$ in less developed countries. Female factors of infertility were more common factors responsible for infertility which are an-ovulatory disorder, tubal factors, endometriosis, uterine and cervical factors; an accurate diagnosis is the key to successful treatment, [1].

The oldest component of the health sector consists of traditional healers and birth attendants who are the de facto providers of primary health care, [2]. The leaves and stem-bark are used for treating swellings in the body (anti-inflammatory). The root-bark and leaves are used in local medicine [3], [4], [1]. A. vogelii has not been scientifically proven to have anti-obesity potential, they have been found to be medicinally useful in other ailments. The seed and bark are used as purgative and antidote for snake bite. The bark and root are used in the healing of dropsy, swellings, oedema, gout and venereal diseases. The leaf-bud serves as antidotes for venomous stings, bites [1]. Alaribe et. al., (2012) [5] demonstrates the anti-plasmodia effects of petroleum ether extract of leaf of $A$. vogelii.

The present investigation was designed to investigate the claims of the traditional medicine practitioners on the usage of Anthocleista vogelii Planch; as fertility enhancer in females, to study the immune-modulating properties, also to study the beneficiary effect of the extract on the liver and to check for other biochemical parameters of the plant using female albino rats as model. [4].

\section{MATERIAL AND METHODS}

2.1 Plant Material: Leaves of Anthocleista vogelii were collected in large quantities from the forests of Imoshe, Ogun State, Nigeria. These was taken for authentication at the Taxonomy Unit, Department of Botany, University of Lagos and obtained the voucher specimen (No: LUH/5652) The leaves was deposited in the herbarium of the Institute and also deposited at the Department of Biochemistry, Lagos State University for future reference.

\subsubsection{Preparation of The Ethanolic Extract: The} leaves of the plant were washed well with water, dried under shade for 14days and powdered to fine grade using electric blender. A batch of $200 \mathrm{~g}$ of powdered material was subjected to cold maceration extraction in $50 \%(\mathrm{v} / \mathrm{v})$ of $1 \mathrm{~L}$ of Ethanol with intermittent shaking at room temperature for 3 days (72 hours). The extract was then filtered, that yielded $620 \mathrm{ml}$ of crude which was lyophilized to get $15 \mathrm{~g}$ of the ethanolic extract corresponding to an extraction yield of $7.5 \%$, stored in the freezer. This extract was re-dissolved in distilled water when ready for administration.

Phytochemical Studies: Phytochemical screening of the extract was carried out using standard procedures to identify the constituents [8] in modified methods of Somkuwar and Kamble [9].

2.1.2 Toxicity Test: Acute toxicity test was performed according to [10]. Nine (9) rats were randomly selected (three per group) and starved overnight. Extract doses of 150,250 and $400 \mathrm{mg} / \mathrm{kilogram}$ body weight were administered to each animal group respectively. The animals were kept under the same natural condition and observed for toxicity signs and mortality for 72 hours. All dosage administered were found to be non-lethal as earlier determine as the safe doses reported by [10].

2.2 Animal Study: Sixty (60) healthy female Wister albino rats of average weight of $100 \mathrm{~g}$ were procured from an inbred stock at University of lbadan, Oyo State, Nigeria. The animals were acclimatized with the laboratory environment for 3 weeks. The experiment was approved by the Ethical committee of the College of Medicine following the edition of the Guide for care and use of Laboratory Animals (National Research Council, 1996).

2.2.1 Animal Treatment: Forty-two (42) female Wister albino rats with an average weight of $120 \mathrm{~g}$ were randomly selected and divided into seven (7) groups with six (6) animals per group. The infertile group was obtained using $\mathrm{N}$-acetylcysteine (NAC) or Micronor (Norethisterone, a proven female contraceptive) used to induce reversible infertility in this rat groups. The treatments for each group were as follows:

Group I: Rats were administered with $1 \mathrm{ml}$ of distilled water once a day for 21 days.

Group II: Rats were administered with micronor (norethisterone) at dose of $20 \mu \mathrm{g} / \mathrm{kg} \mathrm{b.w}$. once a day in a volume of $1 \mathrm{ml}$ for 7 days.

Group III: Rats received NAC (N-Acetylcysteine) at a dose of $1000 \mathrm{mg} / \mathrm{kg} \mathrm{b.w}$. once a day in a volume of $0.74 \mathrm{ml}$ for 7 days.

Group IV: Anthocleista vogelii extract was administered to rats at a dose of $100 \mathrm{mg} / \mathrm{kg} \mathrm{b.w.} \mathrm{once} \mathrm{a} \mathrm{day} \mathrm{in} \mathrm{a}$ volume of $0.25 \mathrm{ml}$ for 21 days.

Group V: Rats were administered with micronor (norethisterone) at a dose of $20 \mu \mathrm{g} / \mathrm{kg}$ b.w. once a day in a volume of $1 \mathrm{ml}$ for 7 days and thereafter administered with Anthocleista vogelii extract at a dose of $100 \mathrm{mg} / \mathrm{kg} \mathrm{b.w}$. in a volume of $0.25 \mathrm{ml}$ for 14 days.

Group VI: Rats were administered with micronor (norethisterone) at a dose of $20 \mu \mathrm{g} / \mathrm{kg}$ b.w. once a day in a volume of $1 \mathrm{ml}$ for 7 days and thereafter 
administered with Anthocleista vogelii extract at a dose of $200 \mathrm{mg} / \mathrm{kg}$ b.w. in a volume of $0.5 \mathrm{ml}$ for 14 days.

Group VII: Rats received NAC (N-Acetylcysteine) at a dose of $1000 \mathrm{mg} / \mathrm{kg} \mathrm{b.w.} \mathrm{once} \mathrm{a} \mathrm{day} \mathrm{in} \mathrm{a} \mathrm{volume} \mathrm{of}$ $0.74 \mathrm{ml}$ for 7 days and thereafter administered with Anthocleista vogelii extract at a dose of $100 \mathrm{mg} / \mathrm{kg} \mathrm{b.w.}$ in a volume of $0.25 \mathrm{ml}$ for 14 days.

All administration was performed orally with the aid of cannula. On completion of administration, the rats in the different groups were anaesthesised with diethyl ether via inhalation. Blood samples were collected from the animals through cardiac puncture and collected into properly labelled EDTA vacutainer tubes and plain tubes for analysis.

2.3.1 Biochemical Assay: Biochemical evaluation of glutamic pyruvate transaminase ALT, alkaline phosphatase ALP, glutamic oxaloacetate transaminase AST, total cholesterol, and total triacylglycerol was done using Randox® biochemical kits.

2.3.2 Hematological Parameters Analysis: WBC (white blood cell) count, absolute count of small cells (lymphocytes), absolute count of middle cells (basophils, eosinophils and monocytes), absolute count of large cells (neutrophils), RBC (red blood cell) count and Hemoglobin (HGB) volume analyses were carried out automatically using the Sysmex® Automated Hematology Analyzer KX-21N.

2.3.3 Statistical Analysis: Data were analyzed using One Way Analysis of Variance (ANOVA, SPSS Version 20) and expressed as mean \pm Standard Error Mean (SEM). Differences between groups were regarded significant at $\mathrm{P} \leq 0.05$ and post-hoc tests were then performed using the Tukey's test.

\section{RESULTS AND DISCUSSION}

\subsection{PHYTOCHEMICAL CONSTITUENT:}

The phytochemical studies revealed the presence of anthraquinones, saponins, flavonoids, alkaloids flavonoids, alkaloids, terpenoids, phenols and Phytosterols.
Table 1: Phytochemical investigation of the leaf of Anthocleista vogelii

\begin{tabular}{|l|c|}
\hline \multicolumn{1}{|c|}{ TEST } & INFERENCE \\
\hline Reducing Sugar & $-\mathrm{ve}$ \\
\hline Terpenoids & $+\mathrm{ve}$ \\
\hline Flavonoids & $+\mathrm{ve}$ \\
\hline Saponins & $+\mathrm{ve}$ \\
\hline Tannins & $-\mathrm{ve}$ \\
\hline Alkanoids & $-\mathrm{ve}$ \\
\hline Cardiac glycosides & $-\mathrm{ve}$ \\
\hline Protein/Amino Acids & $-\mathrm{ve}$ \\
\hline Phenols & $+\mathrm{ve}$ \\
\hline Phytosterols & $+\mathrm{ve}$ \\
\hline \multicolumn{2}{|c|}{ Key: - -ve $:$ absent $,+\mathrm{ve}:$ present } \\
\hline
\end{tabular}

\subsection{EFFECTS ON BIOCHEMICAL PARAMETER:}

The Biochemical parameter levels of the blood obtained from each animal group were assessed and the values obtained are presented in fig 1,2,3 and 4 corresponding to triacylglycerol level, cholesterol level, Alanine transaminase level and Aspartate transaminase level respectively:

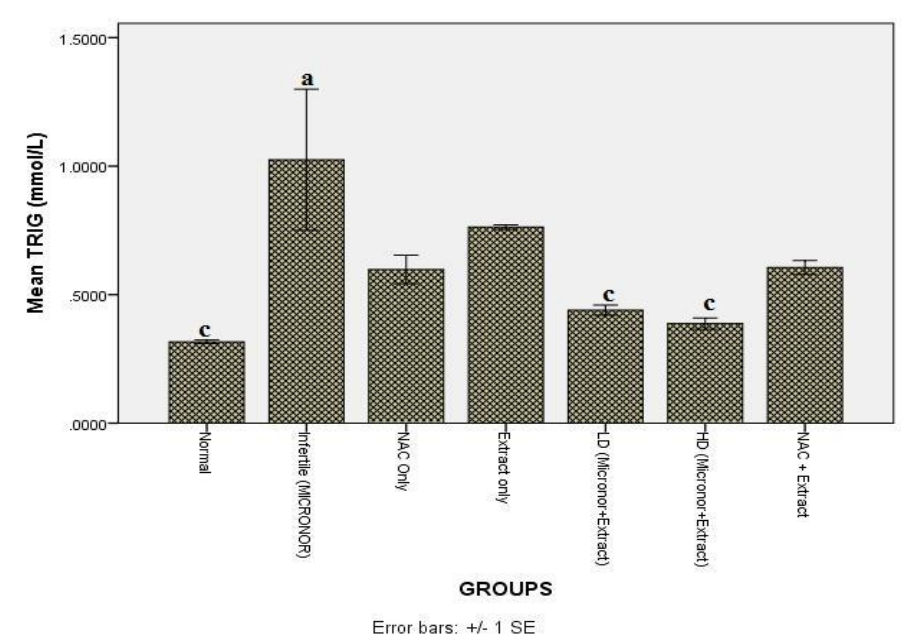

Figure 1: Graphical representation of triacylglycerol level.

a represents significant value compared to Normal group (i.e. Distilled Water), crepresents significant value compared to infertile( micronor) $(P<0.05$, ANOVA post hoc Tukey HSD test). 


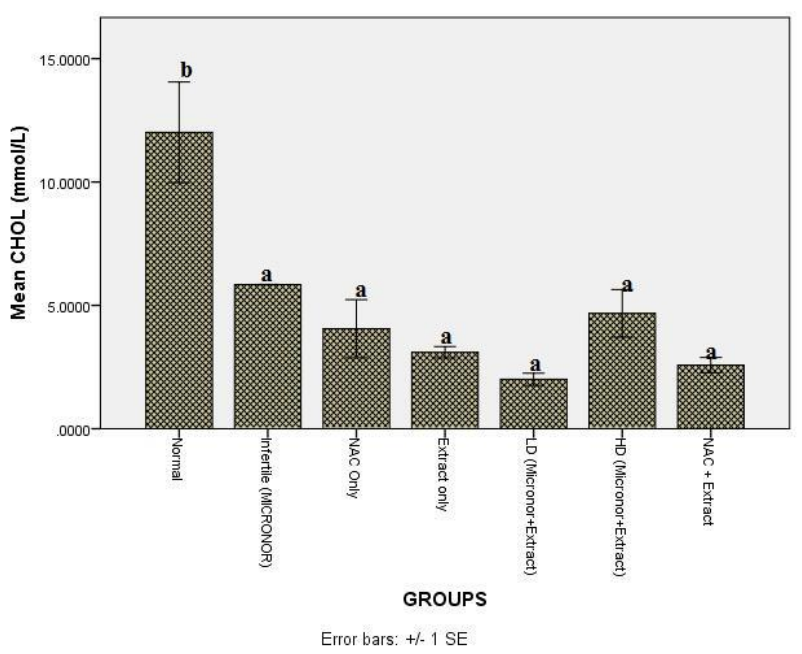

Figure 2: Graphical representation of cholesterol level

arepresents significant value compared to Normal group (i.e. Distilled Water), brepresents significant value compared to extract group $(P<0.05$, ANOVA post hoc Tukey HSD test).

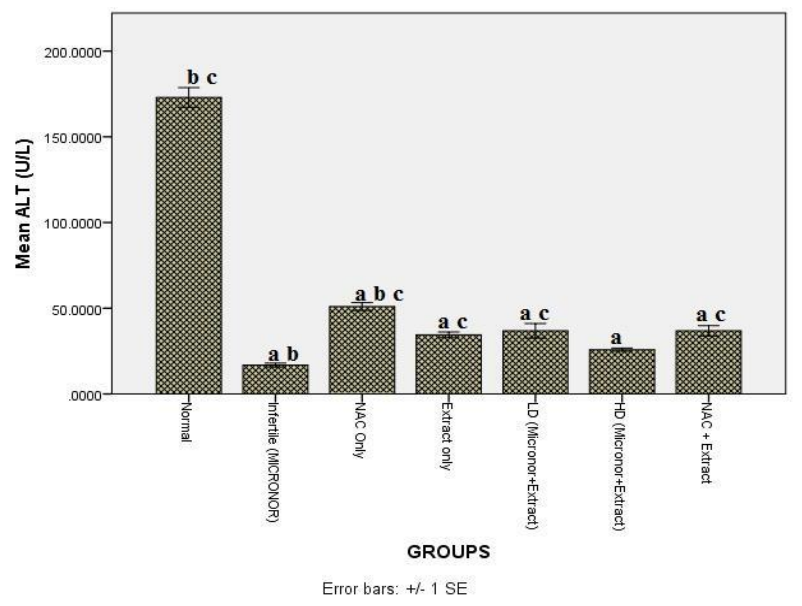

Figure 3: Graphical representation of Alanine transaminase level

a represents significant value compared to Normal group (i.e. Distilled Water), brepresents significant value compared to extract group, crepresents significant value compared to infertile ( micronor) $(P<0.05$, ANOVA post hoc Tukey HSD test).

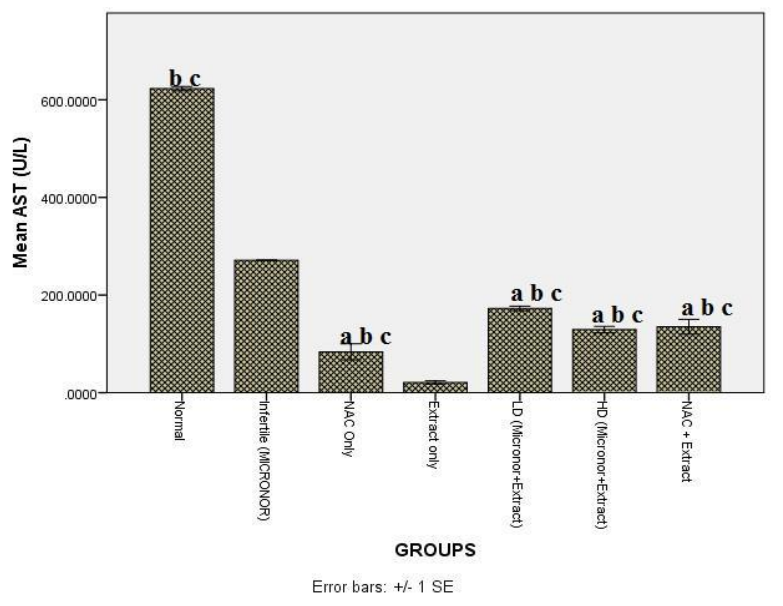

Figure 4: Graphical representation of AST level

a represents significant value compared to Normal group (i.e. Distilled Water), ${ }^{\text {b }}$ represents significant value compared to extract group, ${ }^{c}$ represents significant value compared to infertile (micronor) $(P<0.05$, ANOVA post hoc Tukey HSD test).

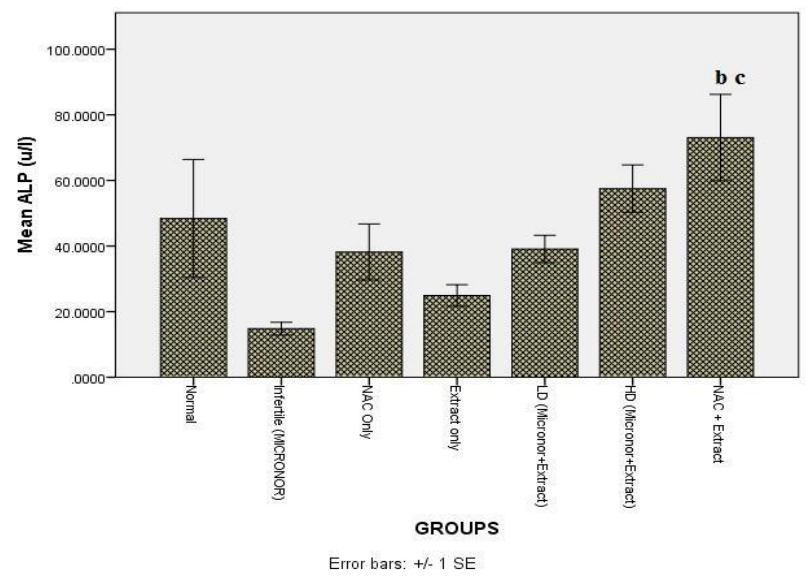

Figure 5: Graphical representation of alkaline phosphate.

b represents significant value compared to extract group, ${ }^{c}$ represents significant value compared to infertile (micronor) $(P<0.05$, ANOVA post hoc Tukey HSD test).

\subsection{Effect on hemoglobin and red blood cell} Effects on hemoglobin and red blood cell (RBC) levels of the blood obtained from each animal group were assessed along other Hematological Parameters. The values obtained are presented in fig 6 and 7 below respectively. 


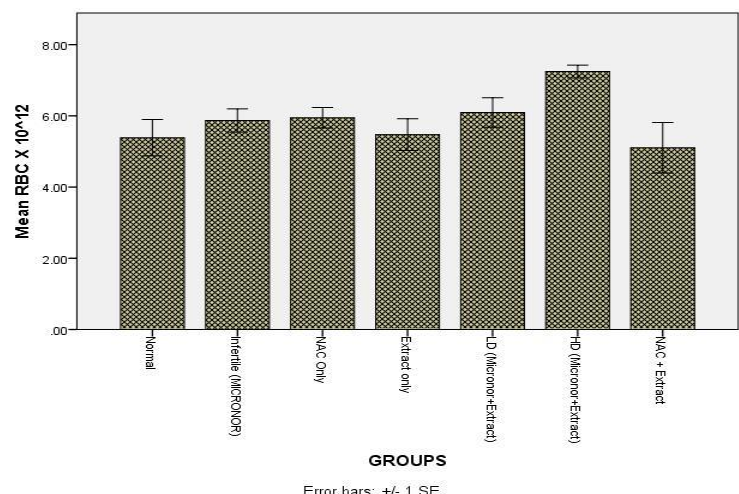

Figure 6: Graphical representation of red blood cell (RBC) count.

a represents significant value compared to Normal group (i.e. Distilled Water) ${ }^{b}$ represents significant value compared to extract group, c represents significant value compared to infertile (micronor) $(P<0.05$, ANOVA post hoc Tukey HSD test).

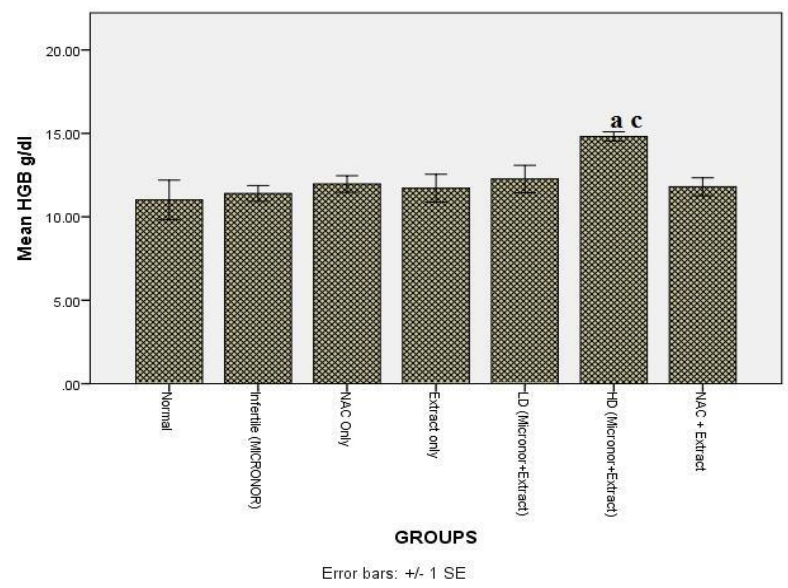

Figure 7: Graphical representation of hemoglobin count.

a represents significant value compared to Normal group (i.e. Distilled Water), ${ }^{\circ}$ represents significant value compared to infertile (micronor) $(P<0.05$, ANOVA post hoc Tukey HSD test).

\subsection{EFFECTS ON LEUKOCYTES}

The leukocytes levels of the blood obtained from each animal group were assessed and the values obtained are presented in fig $8,9,10$, and 11 corresponding to absolute neutrophils count, absolute middle cells count, absolute lymphocytes count and total WBC count respectively:

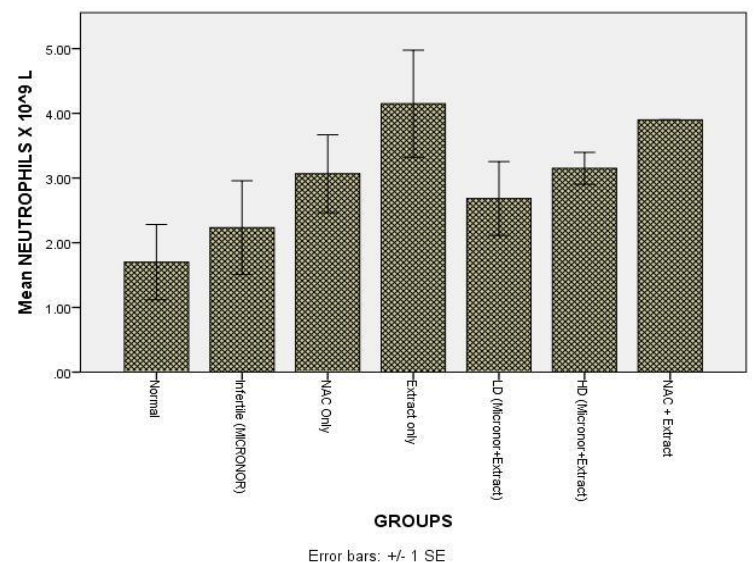

Figure 8: Graphical representation of absolute neutrophils count.

a represents significant value compared to Normal

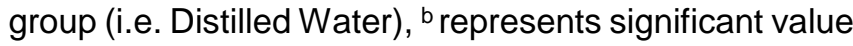
compared to extract group, ${ }^{c}$ represents significant value compared to infertile (micronor) $(P<0.05$, ANOVA post hoc Tukey HSD test.

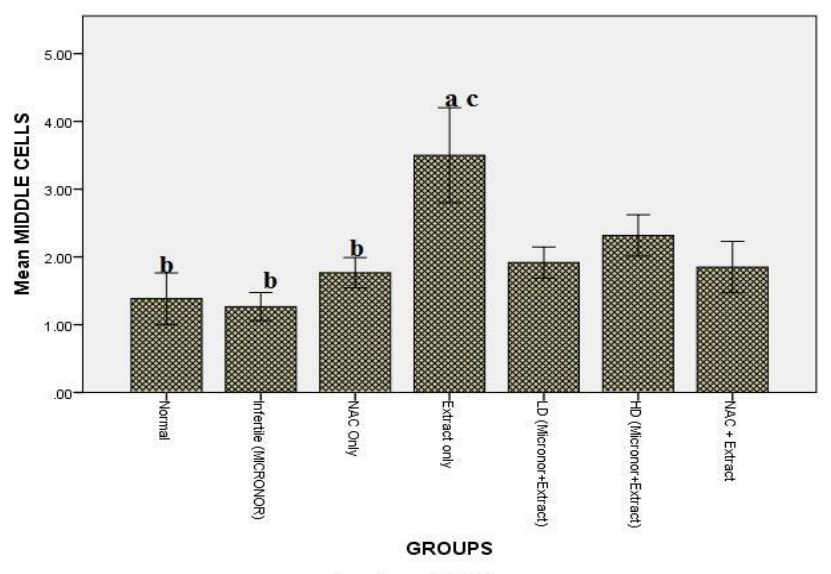

Figure 9: Graphical representation of absolute middle cells count.

a represents significant value compared to Normal group (i.e. Distilled Water), ${ }^{\text {b }}$ represents significant value compared to extract group, ${ }^{c}$ represents significant value compared to infertile (micronor) $(P<0.05$, ANOVA post hoc Tukey HSD test).

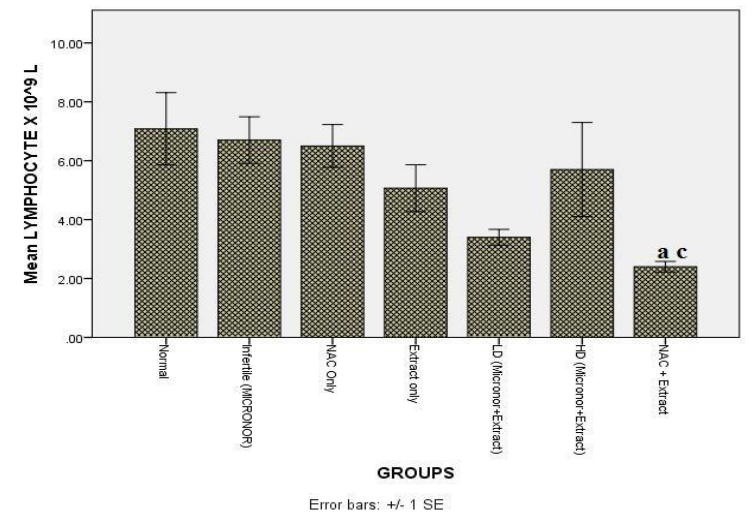




\section{Figure 10: Graphical representation of absolute lymphocytes count.}

a represents significant value compared to Normal group (i.e. Distilled Water), 'c represents significant value compared to infertile( micronor) $(P<0.05$, ANOVA post hoc Tukey HSD test).

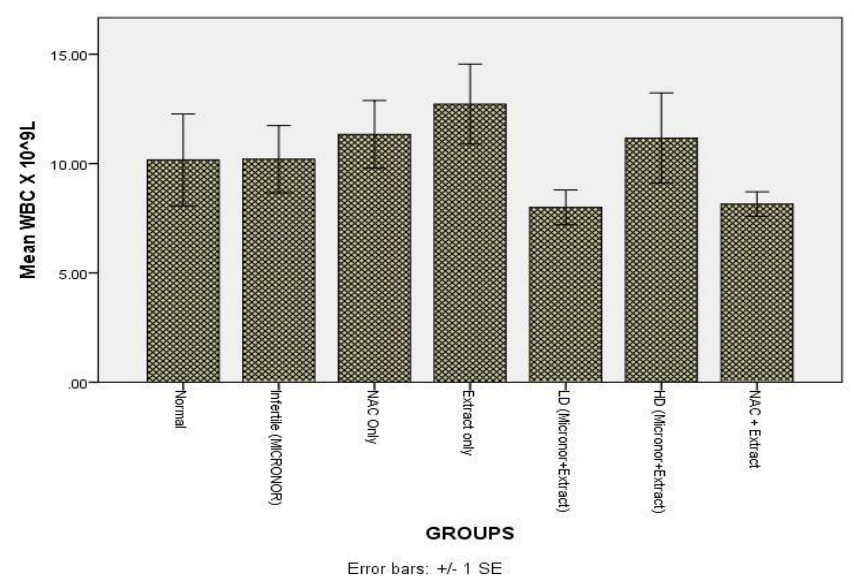

\section{Figure 11: Graphical representation of total WBC count}

a represents significant value compared to Normal group (i.e. Distilled Water), b represents significant value compared to extract group, ${ }^{\mathrm{c}}$ represents significant value compared to infertile( micronor) $(P<0.05$, ANOVA post hoc Tukey HSD test).

Table 1, showed that the ethanolic leaf extract of $A$. vogelii contained saponins, Anthraquinones, Terpenoids, Flavonoids, Alkaloids, phenols and phytosterols. This result is similar to a previous research which shows that the ethanolic root bark extract of $A$. vogelii contained alkaloid, saponin, tannin, steroid and cardiac glycosides. This phytochemistry has been adduced to be responsible for the overall beneficial effect derivable from plants [10]. Saponins are capable of neutralizing some enzymes in the intestine that can become harmful, [7], there was significant reduction in the group of animal administered with the ethanolic leaf extract of anthocleista vogelii at $\mathrm{p}>0.05$.

In the present study, as shown in figures 1 and 2, there was a significant decrease in serum Total cholesterol, and an increase in triacylglycerol (which is not significant) in the group administered with extract. Also, It is well known that excess sugar in the human diet can be converted both into glycerol and fatty acids and, thus into lipids such as triglycerides [7].

It was discovered that the group of animals administered with Anthocleista vogelii extract had significantly lowered total cholesterol compared to the normal control. The Anthocleista vogelii might have significantly decreased the total fat of the group of animals administered with extract which suggest that the body weight may have been restored to normal establish limit necessary for fertility. Some of the chemical constituents, such as saponins, flavonoids and some tri- terpenoids have been reported for their anti-obesity effect in various plants [6].

Saponins as a natural product are also involved in complexation with cholesterol to form pores in cell membrane bilayers [11], as such may be used as anticholesterol agents or cholesterol lowering agent. Thus, it is suggestive that the ethanolic extract of anthocliesta vogelii used in this present study which contains saponins reduced the fat accumulation in the albino rat administered with Anthocliesta vogelii ethanolic extract.

In this study, as shown in figures 3, 4 and 5, the impact of the extract, on the concentration of ALT and AST were determined, which showed significant reduction in their concentration in the serum compared to insignificant increases in the ALP concentration. The liver and kidney constitute the principal organs of detoxification and so represent the first target of all substance in the body. Thus, these two organs are often affected in the event of toxicity. It can be deduced that the administered concentration of extract cannot destroy several hepatic cells because the result shows that the concentration of serum ALT and ASP decreases significantly in the animals treated with extract only, which shows that it may not have had any negative effect on the liver. Indeed, ALT and AST are the markers of the syndrome of cytolysis or destruction of the hepatocyte cells of the liver.

This beneficiary effect on the liver would be due to the antioxidant properties of the extract because the results show a reduction in the hepatic level of enzymes ALT, ASP and AST. This result corroborates with other studies that show high leptin levels in models of rodent D10 obesity [6] [7]. Obesity is a condition of abnormal or excessive fat accumulation in adipose tissue. Thus, by measuring the level of cholesterol, we can directly correlate cholesterol level, Triacylglycerol level, fat mass, obesity and Infertility.

The obtained results in figure 6 , and 7 corresponding to the concentrations of haemoglobin and red blood cell (RBC) from the groups. The results showed that none of parameter was significant.

The obtained results in figure $8,9,10$, and 11 corresponding to absolute neutrophils count, absolute middle cells count, absolute lymphocytes count and total WBC count were analysed. The absolute neutrophils count and the absolute middle cells count had significant high counts in the extract only, compared to other groups which showed that the immunological defense of the groups were potentiated more than others. The absolute middle cells count and absolute lymphocytes count compared with the total WBC count did not show any significant differences except for the NAC plus extracts group that had decreased counts. 


\section{CONCLUSION}

This study tends to support the claims of the traditional practitioner on the use of Anthocleista vogelii to boost reproductive function in female fertility, although the study has not been able to identify the basic principle responsible for this effect.

This research work made known that the ethanolic extract of Anthocleista vogelii is composed of anthraquinones, terpenoids, flavonoids saponins, alkaloids phenols and phytosterols which suggest its potentials to effect the observable changes detected by African traditional medicine practitioners. In a successful pregnancy, however, changes occur within the peripheral blood offers protection from the negative effects of free radicals [7]. It has been shown that oxidative stress is associated with glutathione depletion and damage of the foetus [6]. In addition, it may trigger apoptosis, the consequences of which could be counteracted by the antioxidant properties of NAC [12].

The result also suggest that the ethanolic extract of Anthoclista Vogelii has a beneficiary effect on the kidney and liver by causing a reduction in the level of liver and kidney enzyme in the blood, also the result suggest the potential of the ethanolic plant extract to control and manage the level of cholesterol and triacylglycerol constituents of the total body fat thereby may help in improving reproductive cycle which also support the claims by traditional medicine practitioners and previous research.

\section{ACKNOWLEDGEMENTS}

We acknowledge staff of Biochemistry Department LASU

\section{COMPETING INTERESTS}

Authors declare that no competing interests exist.

\section{AUTHORS' CONTRIBUTIONS}

OSO designed the study, performed the statistical analysis, wrote the protocol, and wrote the first draft of the manuscript. LOA and SA managed the analyses of the study. SA performed the experiments managed the literature searches. All authors read and approved the final manuscript."

\section{ETHICAL APPROVAL (WHERE EVER APPLICABLE)}

"All authors hereby declare that all experiments have been examined and approved by the appropriate ethics committee and have therefore been performed in accordance with the ethical standards laid down in the 1964 Declaration of Helsinki."

\section{REFERENCES}

1. Burkill HM (1985). The useful plants of West Tropical Africa. 2nd edn. Vol. 2. The White friars Press limited, Great Britain. pp. 352-364.

2. De Smet. P.AG.M,.(1991) Is there any danger in using traditional remedies? Journal of Ethnopharmacology .

3. Thomas, R., Tripathi, R., Kamatm S.D. and Kamat, D.V.. 2012. Comparative study of phenolics and antioxidant activity of phytochemicals of $\mathrm{T}$. chebula extracted using microwave and ultrasonication. Int. J. Pharm. Sci. Res. 3(1): 194-197.

4. Francis C, George G, Zohar K, Harinder PS, Makhar LM, Klaus B (2002). The biological action of saponins in animal system: a review. Br. J. Nutr. 88(6):587-605I.

5 Alaribe CSA, Coker HAB, Shode FO, Ayoola G, Adesegun SA, Barimo J, Anyim El, Anyakora C (2012). Antiplasmodial and Phytochemical Investigations of Leaf Extract of Anthocleista vogelii (Planch). J. Nat. Prod. 5: 60-67.

6. Ghanayem BI, Bai R, Kissling GE, Travlos G, Hoffler U (2010). Diet-induced obesity in male mice is associated with reduced fertility and potentiation of acrylamide-induced reproductive toxicity. Biol. Reprod. 82(1):94-104.

7. Fam BC, Morris MJ, Hansen MJ, Kebede M, Andrikopoulos S, Proietto J, Thorburn AW (2007). Modulation of central leptin sensitivity and energy balance in rat model of diet-induced obesity. Diabetes Obes. Metab. 9(6):840-852.

8. Trease GE. Evans WC (1989). Trease and Evans' Pharmacognosy 13th Edition. Published by Bailliere Tindall, pp. 282-396.

9. Somkuwar, D. O. and Kamble, V. A. (2013): Phytochemical screening of ethanolic extracts of stem, leaves, flowers and seed kernels of Magnifera indica L.

10. Ekeanyanwu, R. C, Udeme, A. A, Onuigbo, A. O, And F, Etienajirhevwe O. (2012). Anti-diabetic effect of ethanol leaf extract of Cissampelos owariensis (lungwort) on alloxan induced diabetic rats. African Journal of Biotechnology Vol. 11(25), pp. 6758-6762.

11. Adebayo, S.A., Dzoyem. J.P., Shai, L.J. and Eloff, J.N. 2015. The anti-inflammatory and antioxidant activity of 25 plant species used traditionally to treat pain in southern African . BMC Complement Altern Med. 15:159. DOI 10.1186/s12906-015-0669-5 